The attack can take place, while the boiler is in use, on such of its metallic surfaces as may be wetted by leakage from the boiler itself, or by water infiltrated through the masonry, or derived from the condensation of the aqueous vapor in the gases of combustion by contact with surfaces relatively cold. It can also be produced while the boiler is out of use, by means of the humidity of the air in the flues.

These different origins of the corrosive action, point out the precautions to be taken for preventing its destructive effects. They are only those which should be adopted for the preservation of any apparatus, viz., careful construction, thorough cleaning, and maintenance in good repair.

\title{
ANALYSIS OF THE REPORTS OF THE OPERATIONS OF THE BELGIC ASSOCIATION FOR THE SURVEILLANCE OF STEAM BOILERS, DURING THE YEARS 1873-1874.
}

Translated from the Annales des Mines, of 1876, for the Journar, of the Frankin IN\&TITUTE,

By Chief Engineer Isherwood, U. S. Navy.

As the reports made of the operations of the Belgic Association for the Surveillance of Steam Boilers contain a very complete investigation of the different causes of the deterioration of boilers, a detailed extract will be interesting, leaving to the Chief Engineer of the Association the responsibility for his observations and opinions.

The association commenced on the 30th of December, 1872, and its operations extend over all Belgium. At the end of 1874, that is to say, in the second year of its existence, the number of boilers under the association rose to 1031 ; it was 827 at the end of the first year. 485 boilers were examined interiorly during 1873 ; 278 were in need of repairs, of which 64 required to be immediately taken in hand by reason of the danger they presented. In 1874 the number of boilers examined interiorly was 607 . Many of these examinations revealed serious defects, for which 62 boilers were at once repaired. 
The defects stated were separated, according to their nature, into several categories. These categories, and the number of boilers per category, were as follows :

\begin{tabular}{|c|c|c|}
\hline \multirow{2}{*}{ Nature of the Defects. } & \multicolumn{2}{|c|}{ Number of Defective Boiders. } \\
\hline & 1873. & 1874. \\
\hline $\begin{array}{l}\text { Interior corrosion, } \\
\text { Exterior corrosion, } \\
\text { Cracks or fractures, } \\
\text { Divers causes: } \\
\text { scale, etc., }\end{array}$ & $\begin{array}{r}66 . \\
\text { Not indicated. } \\
\text { Not indicated. } \\
\text { Not indicated. }\end{array}$ & $\begin{array}{c}148 . \\
111 . \\
76 . \\
\text { Number not suf- } \\
\text { ficiently indicated. }\end{array}$ \\
\hline
\end{tabular}

The reports give some observations of detail regarding the nature of the defects, as well as concerning their origin or causes. We reproduce the most important :

\section{INTERIOR CORROSION.}

This kind of corrosion sometimes attacks large surfaces uniformly; sometimes it appears by isolated eavities more or less abundant. The first seems to be the oftenest produced by the use of corrosive water or of scale-preventing remedies. Occasionally it is due to the bad planning of the boiler, as, for example, in those whose design permits the formation of pockets or steam spaces in the feed-water heaters. Of the second, which is stated to be very frequent, the report of 1874 remarks as follows:

"There are often found small isolated cavities in the middle of an otherwise intact plate. These cavities are nearly circular, and have a depth and diameter increasing with their age. They are filled with a black powiler composed, in great part, of the oxide of iron derived from the rusted metal, of sulphates and carbonates deposited from the water in vaporizing, and of a very small quantity of silex. Sometimes they are capped by a yellowish-colored dome."

In some boilers three or four years suffice to perforate a plate, and a dozen years are rarely required.

Occasionally a boiler attacked in that manner presents cavities of all sizes-from those just commencing, up to the largest. Occasionally, too, the cavities are all of one or two sizes, as though they dated from one or two well marked epochs. 
Up to the present time this species of corrosion, which we will call the vermicular, has been observed only exceptionally in plates on which the water is kept in ebullition or agitated. It is found frequently in boilers with feed-water heaters, and in this case the principal cylinders are completely spared, while the coldest of the heaters is the most attacked.

The not heated portions of the boiler and feed-water heaters (for example, the portions resting on the masonry or projecting from the exterior of the furnace), offer strong corrosions of this nature.

When these cavities, instead of being widely apart, are close together, they can form, by their union, a line of fracture.

The engineers of the association have made several analyses, simultaneously, of the feed-water, of the scale produced by it, and of the residues which fill the cavities. Their researches, without reaching an absolute conclusion, have led them to the following presumptions:

Corrosion, under these circumstances, does not seem to proceed from any real acidity of the water, but is exclusively due, according to all appearances, to the action of chlorides or of alkaline salts contained in the water in very small quantities. In five analyses, the products of corrosion contained chloride of iron, which leads to the belief that, in this case at least, chlorides have been formed. It is not impossible that, in other cases, chloride of iron may have been produced, but it would disappear by dissolution in the water of the boiler. ${ }^{\mathrm{i}}$

\section{EXTERIOR CORROSION.}

The exterior corrosions are, according to the reports, one of the greatest causes of the destruction of boilers. Neglecting those which are produced by well-known causes, such as the contact of the metallic plates with the wet masonry of the boiler-setting, and leaks at rivets, seams and cracks, attention is particularly called to the observations relating to the action upon the plates by the products of combustion, an action which has been investigated with much care.

i The oxidizing action of the chlorides of magnesium and of calcium contained in the feed-water of boilers, is a well-known fact. These chlorides are decomposed by the heat of the boilers, and attack either the metallic surfaces in contact with water, or those which are in contact with the steam. 
After a boiler has been in use for some time, says the Report of 1874 , all the surfaces in contact with smoke are covered with a deposit of soot and ash, containing corrosive matter. This deposit has a different appearance, according to its distance from the furnace, and it varies also according to the kind of coal consumed and according to other conditions as yet but imperfectly understood. Its composition changes on being exposed, after the extinction of the fire, to atmospheric air containing aqueous vapor. Neglecting the surfaces exposed to the direct action of the fire, and confining our observation to those at a moderate distance from it, we find the deposit which covers them to consist of three distinct layers. Immediately upon, and strongly adherent to, the metal, is an extremely thin layer of grayish matter, very acid and astringent. Above it is a very acid and astringent black layer. Finally, over both is a white or pinkish layer of matter of extreme tenuity; it is soft to the touch, and, though nearly insipid immediately after the extinction of the fire, son becomes acid and astringent. This last layer is not found on those surfaces where the temperature of the smoke is low.

Twenty-five analyses were made on specimens taken from these different layers at different intervals of time from the moment of extinguishing the fire; some of the specimens were taken from near leaks. All these analyses showed the presence of free sulphuric acid, or of ferruginous sulphates, or of oxide of iron, resulting from the decomposition of the sulphate of iron at a high temperature.

If, in a mixture of water and of the lower layer of the deposit, an iron blade be plunged, it is vigorously attacked with disengagement of hydrogen and formation of sulphate of iron. Nothing can be more natural than the production of this salt, at the contact of the layer and of the metallic plates, when the boiler becomes damp. The entire thickness of the deposit becomes impregnated by imbibition with this sulphate and with free sulphuric acid. On those parts of the boiler surfaces, however, where the smoke has a sufficiently high temperature, and the soot is thick enough to receive the temperature of calcination, the upper layer burns, under the action of the oxidizing gases, and the salts of iron decompose and form the white and pinkish matter which covers the deposit in this case.

Such, according to the engineer-in-chief of the association, is the explanation of the special appearances and varied composition of 
the deposit found on the surfaces of the boiler which are beyond the direct action of the fire.

As long as the boiler is in action, corrosion takes place only on the plates contiguous to leaks, or to damp masonry, or on the plates whose temperature is low enough to condense the aqueous vapor in the smoke; the others are not attacked. But when the fire is withdrawn and the boiler is no longer in use, then the acid formed, and the sulphates of iron and of alumina, attract the humidity of the atmosphere, and when they have attained a certain degree of dilution, the plates commence and continue to rust until only the oxide of iron remains. When a boiler has been out of use over eight days, the corrosion will have become more or less strongly marked, according to the amount of humidity in the air, and in the masonry of its setting.

The influence of the nature of the coal consumed on the degree of corrosion has not yet been ascertained.

III. CRACKS.

Under the head of cracks we do not include those which occur at the edges of plates or in the bends of the flangings, but limit ourselves to those that have been observed to follow through the transverse rivet holes in the lower parts of boilers, some of which cracks have lengths of sixteen, twenty, and even fifty inches. When it is considered that along these lengths the plates are only held by the friction due to the pressure of the rivet-heads-a pressure which is itself lessened by the slipping of at least one of the plates-we are led to ask why explosions do not immediately result from cracks of such size. The Report essays an explanation by remarking that in proportion as the lower plates are strongly heated, they are compressed by reason of the resistance opposed to their expansion by other colder plates. What seems to demonstrate this fact is that nearly all the cracks at the bottom of boilers close when hot and re-open when cold. The danger, however, re-appears as the cooling commences, and it is credible that many of the explosions which have occurred as the fires were dying out, were due to this cause.

IV. DYVERS CAUSES: TOO GREAT INTENSITY OF THE FIRE, SCALE, ETC.

In a great number of boilers formed of connected cylinders (chaudières a bouilleurs) which have been found liable to be burnt, the burning ordinarily occurred at one place, and this place always had a 
constant juxtaposition to the front nozzle or short pipe connecting the boilers. This effect is considered due to the accumulation of sedimentary debris carried by the currents that flow regularly across the nozzles of communication, and deposited by the eddy in the parts relatively tranquil.

The last subject treated by the Reports is boiler-scale, but only a single case is examined : that of the lime-soap deposits due to feeding the boilers with water of condensation from the engines. ${ }^{i}$ The injurjous action of these deposits is shown, and the fruitless attempts described that were made in Belgium to avoid them by the use of tubular apparatus, in which the greasy steam is kept from mixing with the water. Finally, the use of mineral oils for the lubrication of the cylinders is recommended as efficacious-a method adopted some time since by the British Admiralty for the steam cylinders of their vessels.

After having thus reviewed the different defects revealed, during two years of examination, by the boilers under the surveillance of the Association, the Report of $\mathbf{1 8 7 4}$ terminates with the following general observation:

"Because of the little value of the hydraulic test as the sole guarantee of the strength of boilers, periodical examinations by experts are necessary of their interior as well as of their exterior."

Vitreous Phosphate of Lime.-The acid phosphate of lime, described by M. Sidot, is crystallized under the influence of heat. If exposed to a very high temperature, it becomes perfectly vitrified, abandoning part of its elements and descending probably to the condition of tri-basic phosphate of lime, $3 \mathrm{CaO}, \mathrm{PO}_{5}$. It has great refracting power, its index being $1 \cdot 523$; its density, $2 \cdot 6$. It can be worked like common glass, to form lenses, prisms and brilliants, with a strass-like lustre. It resists cold acids, but is attacked by boiling acids and by potash. This property may render it valuable in the art of engraving on glass.-Acad. des Sci.; Les Mondes.

1 The Central Commission in 1874 investigated the accidents attributed to this kind of incrustation. When these soaps are deposited, even in very thin pellicles, on the water-heating surfaces of boilers, they prevent the contact of the water and metal which thus becomes overheated, burnt and ruptured. 